\title{
Joint Task Force Type 1 Myocardial Infarction
}

National Cancer Institute

\section{Source}

National Cancer Institute. Joint Task Force Type 1 Myocardial Infarction. NCI Thesaurus.

Code C119220.

Spontaneous myocardial infarction related to ischaemia due to a primary coronary event such as plaque erosion and/or rupture, fissuring, or dissection. (Universal definition of myocardial infarction, Kristian Thygesen, Joseph S. Alpert and Harvey D. White on behalf of the Joint ESC/ACCF/AHA/WHF T ask Force for the Redefinition of Myocardial Infarction, Eur Heart J (2007) 28 (20): 2525-2538.) 